\title{
¿QUÉ HACER DESPUÉS DE LA GUERRA? LOS PROLEGÓMENOS DEL ESTADO DE BUENOS AIRES $(1853-1856)^{1}$
}

\author{
María Fernanda Barcos \\ Universidad Nacional de La Plata, Concejo Nacional de Investigaciones Científicas \\ y Técnicas \\ (La Plata, Argentina) \\ ORCID: https://orcid.org/0000-0002-7698-8284 \\ mfbarcos@hotmail.com
}

Los procesos de formación de los Estados-Nación latinoamericanos se desplegaron en un contexto de guerra casi constante. En el caso argentino, el fin de la experiencia rosista (18291852) generó una situación de profunda belicosidad en la que diferentes proyectos y elencos políticos se disputaron —en el plano material y simbólico- la legitimidad de organizar el país. Las disputas dilataron la organización nacional y condujeron a la conformación de dos Estados paralelos que se enfrentaron hasta inicios de la década de 1860: La Confederación Argentina y el Estado de Buenos Aires. El presente trabajo estudia la especial coyuntura desatada a partir de mediados de 1853, cuando derrotadas las fuerzas federales que impedían la separación de Buenos Aires, el gobierno de la ciudad homónima comenzó a sentar las bases de un nuevo estado provincial con vocación autonomista. Se analizará especialmente la gobernación de Pastor Obligado para discutir la postura tradicional acerca del consenso rápido y general que obtuvo el nuevo gobierno. Se concluye que el «Sitio» fue un episodio central que no solo afectó a los contemporáneos por los daños que ocasionó, sino porque sus secuelas condicionaron gran parte de las medidas que «fundaron» las bases materiales y simbólicas del «Estado de Buenos Aires».

PAlabRas Clave: Guerras, siglo XIX, Buenos Aires, Estado-Nación, federalismo, pueblos, historia rural.

1. Una versión previa de este trabajo fue presentado en la Jornada de Homenaje al Dr. Jorge Gelman organizada por la Red de Estudios Rurales del Instituto Ravignani, Universidad de Buenos Aires, Argentina. Agradezco a los responsables de la RER la invitación al evento y a los presentes sus comentarios.

[Recibido: 5/6/19; Aceptado: 9/7/19] 


\section{WHAT TO DO AFTER THE WAR?}

\section{The Prolegomans of the State of Buenos Aires (1853-1856)}

The formation processes of Latin American nation-states were deployed in a context of almost constant war. In the Argentine case, the end of the Rosista experience (1829-1852) generated a situation of profound bellicosity in which different projects and political parties disputed -on the material and symbolic level - the legitimacy of organizing the country. The disputes delayed the national organization and led to the formation of two parallel states faced until the beginning of 1860: the Argentine Confederation and the State of Buenos Aires. This article studies the special conjuncture that took place from mid-1853, when after defeating the federal forces that prevented the separation of Buenos Aires, the government of the homonymous city began to lay the foundations of a new provincial state with autonomist vocation. Special attention will be paid to the governorship of Pastor Obligado to discuss the traditional position on the rapid and general consensus obtained by the new government. It is concluded that the «Site» was a central episode that not only affected contemporaries for the damage it caused, but also because its consequences conditioned much of the measures that «founded» the material and symbolic bases of the «State of Buenos Aires».

KEYWORDS: Wars, 19th century, Buenos Aires, State-Nation, federalism, towns, rural history.

\section{Introducción}

Los procesos de formación de los Estados-Nación latinoamericanos se desplegaron en un contexto de guerra casi constante. En el caso argentino, el fin de la experiencia rosista (1829-1852) condujo rápidamente a una situación de belicosidad permanente en la que diferentes proyectos y elencos políticos se disputaron —en el plano material y simbólico- la legitimidad de organizar el país. La imposibilidad de acordar las características de la mentada «organización nacional» condujo a la organización de dos estados paralelos que se enfrentaron durante casi ocho años: La Confederación Argentina y el Estado de Buenos Aires. El presente trabajo estudia los inicios de esta coyuntura de enfrentamiento cuando, derrotada la rebelión federal que puso Sitio a la ciudad de Buenos Aires, en julio de 1853, Buenos Aires inició de modo firme el camino de la autonomía. Nos interesa analizar esta coyuntura porque consideramos que la experiencia del Sitio afectó a los contemporáneos de diferentes maneras y por varios motivos. En primer lugar, los daños que ocasionó la guerra fueron relevantes como así también las consecuencias económicas derivadas de la movilización de hombres. Por otra parte, durante la experiencia del Sitio también se construyeron y reconstruyeron imaginarios en torno a la «barbarie rural» y a «la defensa de Buenos Aires» de fuerte asidero. Así, las secuelas generales que provocó condicionaron buena parte de las medidas que «fundaron» las bases del nuevo Estado de Buenos Aires. 
La temática abordada es relativamente conocida en sus aspectos generales puesto que la historiografía de las décadas de 1950 y 1960 trabajó el periodo y publicó una serie de investigaciones ineludibles, sin embargo, gran parte de estas investigaciones se basaron en caracterizaciones sobre el «caudillismo» y las «formas de hacer política» de los sectores rurales que la historiografía ha reformulado. ${ }^{2}$ Ambas cuestiones ameritan repensar algunos temas y, sobre todo, resignificar la relevancia de estos años prestando atención a los fenómenos políticos desde una óptica que incluya las zonas rurales en toda su materialidad.

En la dirección señalada, en los últimos años se analizaron diferentes aspectos del periodo, por ejemplo: las repercusiones rurales que se produjeron luego de la caída del gobierno de Juan Manuel de Rosas; las expresiones políticas y la simbología federal en los pueblos, las mutaciones en la organización militar de las zonas rurales (particularmente las milicias y las guardias nacionales), las estrategias indígenas del periodo y la diagramación de una nueva territorialidad en las zonas de frontera. También desde la renovada historia política se estudió el rol de la prensa en la década de 1850, la construcción de un imaginario político de pertenencia para el nuevo Estado de Buenos Aires y la discusión sobre la Constitución de ese mismo estado. ${ }^{3}$

2. Saldías, A., Un siglo de instituciones, Buenos Aires en el centenario de la Revolución de Mayo, La Plata, s/e, 1910; Saldías, A., Historia de la Confederación Argentina, Buenos Aires, El Ateneo, T. III, 1951; Cárcano, R., De Caseros al 11 de septiembre: 1851-1852, Buenos Aires, Mendesky, 1946; Allende, A., «Iniciación del gobierno de don Pastor Obligado en la provincia de Buenos Aires en 1853», Trabajos y comunicaciones, n. ${ }^{\circ} 3$, La Plata, 1952, pp. 5-17; Allende, A., «Repercusión de la Revolución del 11 de septiembre en el interior de la provincia de Buenos Aires», Trabajos y comunicaciones, n. ${ }^{\circ}$ 7, La Plata, 1954, pp. 14-18; Allende, A. La frontera y la campaña del Estado de Buenos Aires (1852-1853), La Plata, Fahce, 1957; Díaz, B., Los juzgados de paz de campaña de la provincia de Buenos Aires (1821-1854), La Plata, Universidad Nacional de La Plata, 1959; Minutolo, C., «El Sitio de Buenos Aires y la venta de la escuadra de la Confederación», Boletín del Instituto de Historia Argentina «Dr. Emilio Ravignani», n. ${ }^{\circ}$ 7, Buenos Aires, 1958, pp. 103-132; Scobie, J., El significado de la Revolución de Septiembre, Duke University Press. 1961. Scobie, J., La lucha por la consolidación de la nacionalidad argentina, 1852-1862, Buenos Aires, Hachette, 1964; Bosch, B., Urquiza y su tiempo, Buenos Aires, Ed. Universitaria de Buenos Aires, 1971; Sáenz Quesada, M., El Estado rebelde, Buenos Aires entre 1850/1860, Buenos Aires, Editorial de Belgrano, 1982; Halperin Donghi, T., Proyecto y construcción de una nación (18461880), Buenos Aires, Emecé, 1995.

3. Aramburu, M., «El debate legislativo de la constitución del Estado de Buenos Aires (1854). Los conceptos de nación, soberanía y estado», PolHis, Año 9, n. ${ }^{\circ}$ 17, 2016, pp. 170-209; Barcos, M. Fernanda, «Expresiones políticas y movilización popular en los pueblos de la campaña de Buenos Aires. La Guardia de Luján y el Sitio de Lagos (1852-1854), Nuevos Mundos, Mundos Nuevos, 2012; Barcos, M. Fernanda, «Tratos, batallas y malones. El accionar indígena en la frontera sur durante el sitio a la ciudad de Buenos Aires», Corpus [En línea], vol. 7, n. ${ }^{\circ}$ 1, 2017; Barcos, M. Fernanda, «Las armas en reposo: la intervención del Congreso General Constituyente de 1853 y las disputas por la representación política durante el Sitio a Buenos Aires», Pasado Abierto [En línea], 4 (7), 2018; Caletti, B., «Esa palabra federación, es mágica, atractiva como el imán. Algunos apuntes sobre la cultura política popular en el levantamiento de diciembre de 1852», XII Jornadas Interescuelas Departamentos de Historia, Universidad Nacional del Comahue, 2009; Caletti, B., «Después de la tormenta ¿la calma?: Ejército y Milicias en la campaña porteña tras Caseros», Coordenadas. Revista de Historia Local y Regional, n. ${ }^{\circ}$ 1, 2014, pp. 59-89; Canciani, L., «El coronel Don Benito Machado. Un comandante de Guardias Nacionales en la frontera sur bonaerense [1852-1880]». Mundo Agrario, 12 (24), 2012; Cutrera, M. L., «Que todavía no se ha acabado esto». Sobre el fin del Negocio Pacífico de Indios después de Caseros, Anuario del Instituto de Historia Argentina, n. ${ }^{\circ}$ 13, La Plata, 2013, pp. 125-156; Eujenian, A., «La nación, la historia y sus usos en el 
El gobernador de Buenos Aires, Juan Manuel de Rosas, fue derrotado en febrero de 1852 por una coalición que incluía tanto a antiguos aliados federales como a acérrimos enemigos unitarios. El llamado «Ejercito Grande» fue liderado por el gobernador federal de la provincia de Entre Ríos, Justo J. de Urquiza, e incluyó fuerzas de la provincia de Corrientes, de varios sectores unitarios, del Brasil y de la Banda Oriental. La batalla que había sido rápida proyectaba un triunfo contundente, sin embargo, y a poco de andar, la heterogénea coalición se quebró. Una vez cumplido el objetivo que la había reunido comenzaron las desavenencias, la presencia militar de Urquiza en Buenos Aires se transformó en un problema para la elite de antiguos exiliados porteños que aspiraba a dirigir la provincia. Su impronta federal, el deseo de intervenir en los asuntos de Buenos Aires siendo de Entre Ríos y las rápidas medidas implementadas para organizar constitucionalmente el país, desencadenaron un nuevo enfrentamiento. La rebelión aludida pasó a la historia con el nombre de «Revolución del 11 de Septiembre de 1852» e inició el intento de separación de Buenos Aires del resto de las provincias.

La principal causa fue la negativa de Buenos Aires a asistir al Congreso Constituyente que daría una organización supraprovincial, esto fracturó definitivamente la alianza gestada un año antes y provocó el alejamiento temporal de Urquiza de los asuntos de la provincia homónima. Esto no generó el fin del conflicto, contrariamente, en la ciudad portuaria la situación se agravó pues se produjo una nueva fragmentación. Los problemas se concentraron entre la oficialidad militar (mayormente de pasado rosista) que se debatía entre la lealtad federal hacia Urquiza — con el recelo de ocupar un papel secundario en su administración - y la adhesión a un movimiento que era propio de Buenos Aires pero que estaba liderado por antiguos enemigos a los que tenían que subordinarse. ${ }^{4} \mathrm{La}$ disyuntiva se agudizó cuando Buenos Aires, liderada por Valentín Alsina, planeó expandirse y acabar con la influencia de Urquiza. Muchos de los oficiales se opusieron y fueron desterrados, entre estos se encontraba el general federal Hilario Lagos.

El destierro de Lagos duró poco, la inestable situación de la frontera demandaba militares de experiencia y, debido a ello, se le permitió regresar para ocupar el cargo de Cte. del Dto. del Centro de la campaña. Lagos regresó pero, lejos de obedecer al gobierno, el $1^{\circ}$ de diciembre de 1852 se pronunció contra él.

Esta rebelión inició un sitio por mar y tierra a la ciudad de Buenos Aires que duró casi ocho meses, fue liderada por parte de los generales que habían actuado durante el

Estado de Buenos Aires, 1852-1861», Anuario IEHS, n. ${ }^{\circ} 27$, Tandil, 2012. pp. 57-83; Eujanian, A., El pasado en el péndulo de la política. Rosas, la provincia y la nación en el debate político de Buenos Aires, 1852-1861, Bernal, UNQui Editorial, 2015; Lanteri, Sol y V. Pedrotta, «Tierras, armas y política en la frontera sur bonaerense durante la década de 1850. Los «indios amigos», Maicá y Villa Fidelidad», Anuario del Instituto de Historia Argentina, vol. 18, n. ${ }^{\circ} 1$ [En línea], 2018; Literas, L., El servicio de armas de los habitantes de la campaña durante el Sitio de Buenos Aires. La Guardia de Luján, 1852-1853», Mundo Agrario, vol. 12, n. ${ }^{\circ}$ 24, La Plata, 2012; Míguez, E., Bartolomé Mitre. Entre la Nación y la Historia. Buenos Aires: Edhasa, 2018; Ratto, Silvia, «Haremos lo posible para asegurar y tranquilizar la frontera. La defensa de la frontera bonaerense durante la década de 1850», en J. C. Garavaglia, J. Pro Ruiz y E. Zimmermann (coords.), Las fuerzas de la guerra en la construcción del Estado: América Latina, siglo XIX, Rosario, Prohistoria, 2012, pp. 357-380.

4. Scobie, J., L sea lucha por la consolidación..., cit. 
rosismo y sostenida por la mayoría de la oficialidad federal que, a su vez, movilizó a la fuerza armada y a los vecinos de la mayoría de los pueblos rurales. Los motivos fueron expuestos por Lagos en una Proclama leída desde la plaza del pueblo de la Guardia de Luján. ${ }^{5}$ De acuerdo a ella, la provincia se levantaba en masa contra la ofensiva que el gobierno de Buenos Aires realizaba sobre las provincias vecinas. Cuestión que conducía inexorablemente a una guerra que nadie había autorizado ni deseaba. Entre los argumentos se encontraba también el rechazo al nombramiento del unitario Gral. José María Paz como jefe del ejército y, en documentos posteriores, el pedido de integración de la provincia de Buenos Aires a la Confederación Argentina concurriendo con sus representantes al Congreso Constituyente que se celebraba en la provincia de Santa Fé.

Luego de casi ocho meses, el 14 de julio de 1853 la rebelión fue finalmente sofocada. La férrea organización de la ciudad y el soborno a las fuerzas navales extranjeras que bloqueaban el puerto fueron los elementos que balancearon la relación de fuerzas a favor de los líderes separatistas. Paralelamente, las discusiones que se produjeron entre los jefes militares sobre aspectos de la Constitución sancionada por la Confederación habrían provocado malestar y el inicio de algunas deserciones. Finalmente, la partida de las naves que sitiaban la ciudad por agua al mando del mercenario estadounidense Coe, favoreció el pesimismo y el convencimiento por parte de Urquiza de que el Sitio estaba derrotado.

Concluido el conflicto, sobrevino la desmovilización de las tropas, los poblados rurales encontraban entonces en un estado de desorganización total puesto que no sabían a qué autoridades obedecer y las partidas armadas iban y venían por los campos. Los estragos que dejó la guerra se comenzaron a sentir de múltiples maneras: destrucción de riqueza, pérdidas humanas, inseguridad de los caminos, irregular funcionamiento de las instituciones, rencillas personales, políticas y/o familiares etc. ${ }^{6} \mathrm{La}$ inestabilidad alcanzaba también a la ciudad que había estado en alarma permanente por el encierro y por el peso que tuvieron las levas y los gastos que ocasionó sostener la defensa.

En este contexto general de desorganización, para los dirigentes de la ciudad vencedora algo estaba claro: los sucesos desatados en diciembre no podían volver a repetirse. Con ese objetivo, el gobierno encabezado por Pastor Obligado elaboró un plan más o menos sistemático para ordenar la campaña. Plan que en muchos casos retomaba proyectos de la administración rivadaviana (1824-1827) tamizados por las particularidades que tomó la historia en los años posteriores. Las prioridades eran activar la economía y reorganizar tanto las instituciones administrativas — que permitirían un desarrollo más preciso de la ciudadanía y los derechos de propiedad en clave individual y posesorio- como las represivas — que buscaban instalar un nuevo orden cosas. Recién posteriormente, se intentó generar nuevos consensos entre la población rural a través de negociaciones políticas. Todas estas estrategias tuvieron, como veremos, éxito diverso y se ensamblaron con

5. AGN, Farini, Correspondencia Lagos (en adelante AF, CL), Leg. 262, 1. ${ }^{\circ}$ de diciembre de 1852.

6. Barcos, M. F., «Tratos, batallas y malones...», cit. 
cuestiones que no derivaron necesaria ni directamente con la cuestión facciosa, por ejemplo, intereses económicos, enfrentamientos familiares, disputas por el manejo de los dispositivos de poder, violencia electoral y otras.

\section{El fin del Sitio y el nuevo orden de cosas}

Con el fin del Sitio a la ciudad de Buenos Aires las fuerzas militares vencedoras comenzaron a ocupar la campaña comunicando a los jefes y oficiales rebeldes que el gobierno otorgaría «olvido y perdón» pero para ello debían salir en 24 horas a sus nuevos destinos. Sin embargo, luego del desbande provocado por la rendición, la medida prometida no se cumplió y se persiguió a los sublevados al tiempo que se mandó embargar los bienes de los principales «cabecillas», los coroneles Hilario Lagos, Gerónimo Costa y Benjamín Méndez.

El fin de la guerra y de la ocupación generó en la población de la ciudad un clima de exaltación y triunfalismo que fue visiblemente expuesto, sin embargo, el triunfo no borró sus secuelas. ${ }^{7}$ La memoria de lo sucedido en 1828, y los recientes acontecimientos, evidenciaban que los pueblos rurales eran un escenario privilegiado para el desarrollo de rencillas políticas y sublevaciones y, por eso, las autoridades del futuro Estado de Buenos Aires intentaron en los meses siguientes «controlarlos» rigurosamente. $^{8}$

Luego de la muerte del gobernador Manuel Pinto, y del interinato de Lorenzo Torres, Pastor Obligado fue designado oficialmente gobernador, su pasado rosista fue interpretado inicialmente como un signo de moderación para la revitalizada «opinión pública» de Buenos Aires. El nuevo gobierno se encontró inmediatamente inmerso en una crisis económica significativa producto de los gastos ocasionados para solventar la guerra, la paralización del comercio y la pérdida de riqueza material al interior de la campaña. Allí la dispersión de las haciendas, junto con la escasez de brazos para las faenas, generó un problema de magnitud. Sumado a esto, los testimonios dan cuenta de la «inseguridad de los caminos» producto de la desmovilización de las tropas y la presencia de salteadores. La ciudad no se encontraba tampoco en un momento apacible, entre la opinión pública la euforia por el triunfo fue dando paso a la preocupación por la débil relación que se empezaba a generar con la Confederación Argentina y el pedido de juzgar los «críme-

7. Lettieri, A., La construcción de la República de la opinión. Buenos Aires frente al interior en la década de 1850, Buenos Aires, Prometeo, 2006; Eujanian, A., El pasado en el péndulo de la política..., cit.

8. En cuanto al primer punto, varias fuentes ilustran la participación que tenían los pobladores rurales en la vida política de sus vecindarios y cómo los vaivenes de ésta repercutían en sus vidas. Por supuesto que algunos testimonios estaban teñidos de los asuntos de la cotidianeidad local o incluso rencillas personales y familiares. No obstante, esto no debería distraer la atención sobre las formas de expresión de la opinión. Ver por ejemplo, González Bernaldo, Pilar, «Sociabilidad, espacio urbano y politización en la ciudad de Buenos Aires (1820-1852)», en Hillda Sabato y A. Lettieri (Comps.). La vida política en la Argentina del siglo XIX. Armas, votos y voces, Buenos Aires, FCE, 2003, p. 202. En cuanto los acontecimientos que sobrevinieron luego del fusilamiento de Dorrego y durante la rebelión rural de 1828 ver: Fradkin, R., La historia de una montonera. Bandolerismo y caudillismo en Buenos Aires, 1826, Buenos Aires, siglo XXI, 2006. 
nes desatados durante rosismo» a lo que se sumó el enjuiciamiento a los partícipes del Sitio. ${ }^{9}$

La delicada situación política en los vecindarios, que días atrás estaban bajo mandos federales, y una frontera mal defendida preocupaban entonces al nuevo gobierno. En esa línea, desde 1853 el periódico El Nacional anunciaba la visita del gobernador a los pueblos del Norte y Oeste de la campaña, viaje que finalmente se efectuó en 1854. Resulta interesante la descripción que el cronista de La Tribuna hacía sobre la llegada del gobernador a la Guardia de Luján, allí lo recibieron: «[...] con las demostraciones más simpáticas. Podría creerse muy bien, quería con ellas descargarse de la responsabilidad histórica que pesaba sobre él [el vecindario] por haber sido el lugar elegido por Lagos para dar el primer grito de rebelión». ${ }^{10}$

Los viajes a las vecindades rurales efectuados por los gobernadores de Buenos Aires fueron un intento de avanzar en el proceso institucional mediante una innovadora forma de resolución de conflictos. ${ }^{11}$ Si bien estas presencias muestran un intento de acercamiento de los dirigentes porteños a la cotidianeidad de los pueblos rurales, cabe preguntase qué alcance concreto pudieron tener en relación con el peso que tuvo el despliegue coercitivo de estos años. ${ }^{12}$ Esto no significa considerar que no hubo elementos de negociación, los hubo y los viajes fueron uno de ellos, sino que éstos se desplegaron después de fuertes dispositivos de ordenamiento y tuvieron —como eje principal— un reconfigurado pacto político social. En las páginas siguientes trataremos de avanzar en esta hipótesis.

\section{Alcances y límites de la reorganización de la campaña}

\section{El control politico-territorial: hombres, recursos, instituciones}

La situación de la campaña al terminar el Sitio era deprimente por los estragos que había causado la guerra. Los auxilios y los embargos, gracias a las cuales se pudieron abastecer las tropas, generaron la ruina de los establecimientos rurales. ${ }^{13}$ Durante el conflicto las

9. Barcos, M. F., Pueblos y ejidos de la campaña bonaerense: una bistoria sociojurídica de los derechos de propiedad y la conformación de un partido: Mercedes, 1780-1870. Rosario, Prohistoria, 2013.

10. Barcos, M. F., «Expresiones políticas y movilización popular...», cit.

11. Zubizarreta, Ignacio, «Politización y transformaciones sociales en los pueblos de campaña del Estado de Buenos Aires, 1852-1861», Diálogos Revista Electrónica de Historia, 19 (2), 2018 [En línea] y, del mismo autor, «Whistle-stop en carruaje: Los viajes de los gobernadores a los pueblos bonaerenses, 1854-1858», Población E Sociedad [en línea], vol. 26 (1), 2019, pp. 120-143.

12. Míguez, E., «Guerra y orden social en los orígenes de la nación argentina, 1810-1880», Anuario del IEHS, n. ${ }^{\circ}$ 18, 2003, pp. 17-38; Garavaglia, J. C., «De Caseros a la guerra del Paraguay: el disciplinamiento de la población campesina en el Buenos Aires posrosista (1852-1865)», en Garavaglia, J. C., Construir el estado, inventar la nación. El Río de la Plata, siglos XVIII-XIX, Buenos Aires, Prometeo, 2007, pp. 311-342. Garavaglia, J. C., La disputa por la construcción nacional argentina. Buenos Aires, la Confederación y las provincias (18501865), Buenos Aires, Prometeo, 2015.

13. Durante el Sitio, fueron embargadas las propiedades de varios estancieros que durante la contienda se 
quejas de los estancieros fueron constantes pero sólo en algunos pocos casos las medidas fueron suspendidas. Sumado a este drenaje, en febrero de 1853 se produjo un malón feroz que drenó aún más las existencias de ganado de la provincia, sobre todo las del Sur. ${ }^{14}$

Luego de finalizada la guerra la situación se tornó aún más caótica ya que abundaban las matanzas y las reventas de ganado extraviado y de marcas de estancias embargadas. Para intentar recomponer la situación anteriormente citada, el nuevo gobierno prohibió vender ganado de otra marca que no fuera la del vendedor, ordenó la suspensión de las faenas en las graserías y saladeros (excepto los de la ciudad) y prohibió que se abrieran nuevos establecimientos. Pero el problema no desapareció ya que se tornaba indispensable proveer de alimento a las tropas asignadas a la frontera. El mismo caos existía en relación con las caballadas patrias, desde la batalla de Caseros, y más aún desde el motín de diciembre, vagaban por toda la campaña caballos dispersos. Para paliar la situación se ordenó a los comandantes militares y jueces de paz recolectarlos y conservarlos en invernada. ${ }^{15}$

La historiografía tomó estos decretos como si fueran un hecho y como parte de los progresos que sobrevendrían en la campaña con el nuevo gobierno, pero las fuentes inéditas matizan esta idea. En septiembre de 1853 el Comandante Militar de Fuerte Federación comunicaba al gobierno que en dicho paraje no existían suficientes raciones ni comestibles para la manutención de tropa e indios amigos, cuestión que hacía inviable la manutención de hombres asentados a 15 leguas de distancia. La respuesta no se hizo esperar, se debían disminuir las raciones de carne a tres para jefes, dos para oficiales y una para indios. En cuanto a los cueros robados, el Juez de Paz del partido de Azul denunciaba que los mismos se trasladaban al pueblo de Tandil para que allí los compraran los hacendados del partido de Tapalqué «por nada». ${ }^{16}$

Otra cuestión no menos importante para avanzar en la reorganización de la campaña se relacionó con la división parcelaria de la provincia. Ya en noviembre de 1853 se solicitaba a los jueces de paz que «por todos los medios posibles» averiguasen los límites de sus partidos debido a que en el futuro se quería evitar tener partidos de tamaño desmesurado que hicieran imposible la vigilancia y control. De manera concomitante se planteaba la idea de construir un nuevo Registro Gráfico, requisito indispensable para el establecimiento del sistema municipal que ya estaba en carpeta. ${ }^{17}$ El interés también se relaciona-

habían declarado abiertamente a favor de la ciudad. Los embargos fueron una constante en la mayoría de los conflictos. Ver por ejemplo: Banzato, Guillermo, «Las confiscaciones y embargos de Rosas en Chascomús, 1840-1852», Cuadernos del PIEA, n. ${ }^{\circ}$ 15, UBA, 2001, pp. 5-32; Gelman, Jorge y M. I. Schroeder, «Juan Manuel de Rosas contra los estancieros: Los embargos a los «unitarios» de la campaña de Buenos Aires», Hispanic American Historical Review, 83:3, 2003, pp. 487-520.

14. Barcos, M. F., «Tratos, batallas y malones...», cit

15. Registro Oficial del Estado de Buenos Aires, Buenos Aires, Imprenta de «El Orden», 1854, p. 205.

16. Cabe aclarar que Azul y Tapalqué eran partidos lindantes. AGN, Estado de Buenos Aires, Gobierno, 5686.

17. En octubre de 1853 Domingo Olivera presentó un proyecto de municipalidades a la Sala de Representantes. Sobre el tema ver Canedo, Mariana, «Mucho más que una cuestión de medidas. Los agrimensores del Departamento Topográfico por los pueblos del Estado de Buenos Aires. La comisión del Norte, 1854-1856.» 
ba con la reformulación del impuesto de Contribución Directa efectuado en diciembre de 1853, el cambio consistía en que a partir del año siguiente quedaría abolida toda contribución que no fuera sobre capitales en bienes raíces. ${ }^{18} \mathrm{La}$ crisis económica de la campaña y la necesidad de generar consensos obligó al gobierno a reducir la presión impositiva sobre los ramos de agricultura, ganadería y comercio, entonces un mejor conocimiento del número de propietarios por partido para cobrar el impuesto se tornaba indispensable. ${ }^{19}$ La construcción del registro, sin embargo, se pudo efectivizar 10 años después.

El control sobre las actividades de vecinos y funcionarios fue otra ocupación del nuevo gobierno que operó mediante instrucciones. Desde el partido de la Guardia de Luján, cuna de la rebelión, José María Flores prohibió a los pobladores usar la «divisa punzó», orden que luego se hizo extensiva para toda la provincia mediante un decreto. ${ }^{20}$ Cuando se trasmitió la orden al juez de paz de la Guardia se agregaba la siguiente apreciación:

El infrascrito al transcribir a U. el referido decreto, le recomienda muy especialmente su más puntual cumplimiento en ese Partido, pues es indudable la necesidad de que en todo el territorio de la Provincia no vuelvan a aparecer jamás ni aún vestigios de la odiosa división que desgraciadamente ha existido hasta hoy entre los hijos de un mismo pueblo, simbolizadas por las divisas de guerra que ha incendiado la Provincia y aún la República, ocasionado los innumerables males de todo género que ha sufrido y que habiendo sido de tan funestas consecuencias, deben ya cesar de todo punto para arribar cuanto antes a cimentar el orden, la tranquilidad y la felicidad permanente de nuestra Patria bajo el imperio de la ley y la justicia. Deberá procurar por los medios que le dicte su prudencia, hacer que estas ideas cundan en todos los habitantes de ese Partido. Pues éste es uno de los medios más seguros de obtener la unión de todos para lograr la paz perpetua en la Provincia. Dios guarde a V. m. a. Lorenzo Torres. ${ }^{21}$

La inestabilidad en el ejercicio de las tareas de los jueces de paz durante esos años fue constante. Finalizada la rebelión se repuso a la mayoría de los jueces que habían sido removidos por Lagos. ${ }^{22}$ De esta manera el gobierno intentaba asegurarse no contar con «elementos» — término muy utilizado por esos días- poco proclives a la obediencia al nuevo gobierno. Un dato interesante respecto de la reposición de jueces fue que, a pesar de la necesidad de controlar los vecindarios, en algunos partidos se mantuvo a los funcio-

En Garavaglia, Juan Carlos y Pierre Gautreau (comps.), Mensurar la tierra, controlar el territorio. América Latina siglos XVIII y XIX, Rosario, Prohistoria Ediciones, 2011, pp. 259-294.

18. Registro Oficial de la provincia de Buenos Aires, Buenos Aires, Imprenta de «El Orden», 1853, p. 167.

19. Sobre el tema ver: Gelman, Jorge y Daniel Santilli, «¿Cómo explicar la creciente desigualdad? La propiedad de la tierra en Buenos Aires entre 1839 y 1867», en Gelman, Jorge (coord.), El mapa de la desigualdad en la Argentina del siglo XIX, Rosario, Prohistoria, 2011.

20. AGN, Secretaria de Rosas, Orden del 17 de julio de 1853. Registro Oficial..., cit., Decreto del 23 de julio de 1853, pp. 504-505.

21. Archivo Histórico Judicial de Mercedes, JDP, Nota del 26 de julio de 1853. El subrayado es nuestro.

22. Estos a su vez habían sido designados por Alsina luego del 11 de septiembre de 1852. 
narios que actuaron durante el Sitio hasta tanto se pudiera realizar la elección prevista por la ley. ${ }^{23}$ Decisión que fue duramente criticada en los periódicos La Tribuna y El Nacional de esos meses. Los límites en el accionar sobre los poblados no fue un problema exclusivo del nuevo gobierno, durante el Sitio algunas reposiciones se suspendieron por presión de otros jueces o sugerencia de la oficialidad. En este sentido, pareciera que algunas figuras locales eran lo suficientemente fuertes para mantener sus posiciones en los sucesivos cambios de coyuntura política. ${ }^{24}$

Luego de esto, el gobierno ordenó a los funcionarios «que hicieran entender a los paisanos que debían volver a sus hogares a entregarse pacíficamente a sus faenas ya que se había concedido el completo olvido y perdón por los errores políticos». Coincidimos con Garavaglia cuando aludiendo a esta orden expresa en su libro sobre Areco: «Pocos escritos muestran con tanta claridad hasta qué punto para los liberales de Buenos Aires los paisanos eran algo bien distinto a los ciudadanos; mientras éstos podían formar comisiones para decidir, controlar y reprimir, aquellos debían entregarse pacíficamente a sus labores y tareas». ${ }^{25} \mathrm{~A}$ estas medidas le siguieron la regulación de las contratas y la insistencia en apresar «vagos» para los cuerpos de línea.

En los años posteriores se agregaron otras medidas administrativas que afianzaron el control político territorial buscado: la reorganización de la justicia letrada, la puesta en funcionamiento de las municipalidades, el restablecimiento de las comisarías y la creación de las prefecturas. ${ }^{26}$ Todas estas medidas tuvieron que necesariamente inscribirse en instancias de negociaciones y acuerdos con los poderes locales. En cuanto a las primeras elecciones municipales, Canedo analizó las dificultades de su «instalación» poniendo de relieve la perspectiva centralista de una legislación basada en la presunción de que las comunidades rurales tenían poca o nula experiencias en el gobierno local. Su trabajo también da cuenta de las rencillas en torno a las candidaturas y como en este plano operaron asimismo las luchas facciosas del pasado reciente. No obstante esto, resalta la importancia paulatina de la formalización de las elecciones en ciudad y campaña como un aspecto novedoso del Estado de Buenos Aires. ${ }^{27}$

No vamos a detenernos en las restantes disposiciones judiciales porque exceden los objetivos de este artículo, además varias de ellas forman parte de lo que, creemos, fue una segunda etapa en la dinámica del Estado de Buenos Aires.

23. Registro Oficial..., cit., Decreto del 17 de agosto de 1853.

24. Garavaglia, Juan Carlos, San Antonio de Areco, 1680-1880, Rosario, Prohistoria, 2009; Barcos, M. Fernanda, «Tratos, batallas y malones...», cit.

25. Ibidem, p. 411.

26. Yangilevich, Melina, «Prefecturas, comisarías de campaña y construcción estatal en la Provincia de Buenos Aires (Argentina) a mediados del siglo XIX», Secuencia, núm. 102, 2018, pp. 70-99, Canedo, Mariana, «...en la Campaña se ha despertado un espíritu maligno». Estrategias políticas y divisiones sociales en las primeras elecciones municipales (Estado de Buenos Aires, 1855)», en este mismo número de Illes $i$ Imperis, 2019; Corva, M. A. Constituir el gobierno, afianzar la justicia. El Poder Judicial de la provincia de Buenos Aires (18531881), Rosario/Buenos Aires, Prohistoria Ed.-Instituto de Historia del Derecho, 2014.

27. Canedo, Mariana «...en la Campaña se ha despertado un espíritu maligno...», cit. 


\section{El control militar: comandancias de frontera y guardias nacionales}

La naturaleza de las comandancias de frontera era un tema que estaba en discusión desde antes del Sitio, para el ministro Escalada esta institución era la que enseñaba la anarquía a los caudillos y, debido a ello, proponía su separación en dos departamentos. ${ }^{28}$ En la misma línea, José María Flores, Jefe del Dto. Norte, explicaba el excesivo poder que se tenía desde ese cargo al punto tal que era la comandancia el «... origen de las revoluciones, porque ponía en manos de un hombre la suerte de la Provincia, desde que cada Departamento podía movilizar un cuerpo del Ejército». ${ }^{29}$ Proponía entonces disolverlas y que cada jefe de regimiento se comunicara directamente con el Ministerio de Guerra. Sin embargo, el gobernador Obligado se opuso al proyecto de Flores argumentando la difícil situación en la que se encontraba la frontera. ${ }^{30}$ De esta manera siguieron vigentes las comandancias de los departamentos Norte, Centro y Sur.

Para acelerar la desmovilización de hombres, el Jefe de la Comandancia del Norte, Manuel Hornos, dirigió una circular a los jueces de paz donde se informaba el fin del servicio militar y la restauración de los jueces de paz como autoridades civiles y policiales; al tiempo que visitó varios pueblos para recabar información sobre el estado de cosas. ${ }^{31}$ Al llegar a Buenos Aires, hizo hincapié en la necesitad de reorganizar las Guardias Nacionales y retirar de los partidos a los hombres que habían sido «jefes de los rebeldes» para así tranquilizar al paisanaje. ${ }^{32}$

El Jefe del Dto. Sur, Martínez, también se dedicó a conocer el estado de sus departamentos. Para ello consultó a Pedro Rosas y Belgrano sobre la relación de fuerzas, armamento y demás con la que contaba para cubrir la parte de la frontera de Azul. ${ }^{33}$ En la nota aclaraba que, en virtud de sus antecedentes, no le daría órdenes. ${ }^{34}$ La aclaración es importante porque resalta la importancia que seguía teniendo Pedro Rosas y Belgrano en el Sur a pesar de los sucesos acaecidos durante el Sitio. ${ }^{35}$ Su regreso al Azul fue relatado pormenorizadamente por El Nacional:

28. Durante la breve gobernación de Alsina ya se había realizado una nueva división de las comandancias con la creación del Dto. Centro.

29. Citado por Allende, A., La frontera y la campaña..., cit.

30. Mensaje del Gobierno Provisorio de la provincia de Buenos Aires a la Legislatura, El Nacional, 3 de octubre de 1853, p. 2. Col. 1.

31. Pergamino, San Nicolás, Chivilcoy, Bragado, 25 de mayo, Las Flores, Federación (Junín), Salto.

32. Allende, A., La frontera y la campaña..., cit.

33. AGN, Gobierno, Comandancia de los departamentos Centro, Norte y Sur. 9 de septiembre de 1853.

34. Hijo de Manuel Belgrano, fue adoptado por Juan Manuel de Rosas y con los años se convirtió en un importante militar, en hacendado e integró la legislatura provincial. Luego de la caída de Rosas siguió siendo el juez de paz de Azul por orden directa de Urquiza pero luego fue nombrado Cte. del Regimiento de Caballería Número 11, con sede en Azul. Cuando estalló la rebelión de Lagos estaba en la ciudad de Buenos Aires desde donde apoyó al separatismo porteño.

35. Pedro Rosas se enfrentó a las tropas de Lagos en la Batalla de San Gregorio. En dicha oportunidad los indios amigos de ambos bandos desistieron de participar y las tropas federales resultaron vencedoras. Pedro Rosas fue capturado cuando emprendía la retirada terminó preso apresado por los sitiadores. 
Fue recibido por el vecindario como el hijo predilecto de la campaña del Sud, con los brazos abiertos y en medio de víctores entusiastas [...] Bailes costeados por el pueblo, serenatas, repiques y un incendio de cohetes, han sido la salva general del pueblo del Azul al benemérito Coronel D. Pedro Rosas y Belgrano.

El Gobierno y la Provincia de Buenos Aires ven en él la más positiva garantía del orden y tranquilidad en las dilatadas regiones del Sud. A su presencia los indios se han apaciguado, y los caciques han ido a brindarle con el deseo de una paz permanente. ${ }^{36}$

El periódico al mismo tiempo que ensalzaba la figura de Pedro Rosas se dirigía puntualmente a minimizar los rumores respecto de la animosidad que existía en la campaña por el nuevo gobierno: «Aquellos que [...] pretenden sembrar entre nosotros la desconfianza y confusión, haciendo aparecer a la campaña en disidencia con el Gobierno, y en continúa agitación; mírense en ese espejo, y dígannos como explican ese júbilo entusiasta del digno vecindario de Azul.» ${ }^{37}$

La medida de apartar a los jueces de las funciones del reclutamiento terminó tornándose apresurada cuando, en septiembre de 1853, se dispararon las alarmas por la posibilidad de una invasión indígena. En dicha oportunidad se ordenó reunir 100 hombres por distrito para ir a la frontera. Los jueces de paz de los partidos de Vecino y Tuyú respondieron que esto era imposible porque los hombres del partido estaban bajo contrata en las haciendas (esta medida había sido exigida por el mismo gobierno) y ahora los jueces de paz no tenían poderes para realizar levas. ${ }^{38}$ En función de las respuestas recibidas, Martínez relataba al ministro Escalada la poca autoridad que tenían con los jueces de paz de los partidos y el grado de insubordinación en la que se encontraban los paisanos. ${ }^{39}$ Por tanto, la tranquilidad en la que se encontraban los vecindarios de acuerdo a la propaganda de La Tribuna y El Nacional no era general puesto que los actos de deserción y desobediencia formaban parte de la cultura de resistencia cotidiana de los sectores populares.

El fracaso de la medida fue tal que Martínez decidió suspenderla ayudado por la falsa alarma de invasión. ${ }^{40}$ Los oficiales y jueces planteaban que la única solución para reunir hombres era formar de una vez por todas la Guardia Nacional y el Cuerpo de Caballería de Línea porque, aun logrando reunir a los «sin ocupación», éstos no serían más que «masas informes y una montonera». ${ }^{41}$

Es importante aclarar que la formalización de las Guardias Nacionales llevó varios años debido a la demora en sistematizar el servicio, cuestión que se debió, entre otras cosas, a la necesidad de dar cierto respiro a una población harta de reclutamientos. ${ }^{42}$

36. El Nacional, 10 de septiembre de 1853, p. 2, col. 4.

37. Ibidem.

38. AGN, Gobierno, Comandancia, 12 de noviembre de 1853.

39. AGN, Gobierno, Comandancia, 19 de noviembre de 1853.

40. AGN, Gobierno, Comandancia, 24 de noviembre de 1853.

41. AGN, Gobierno, Comandancia, 8, 13 y 19 de noviembre de 1853 .

42. Si bien desde marzo de 1852 se habían disuelto las milicias, y se había decretado la formación de la 
Máxime teniendo en cuenta que el apoyo original que obtuvo la oficialidad federal para la rebelión encabezada por Lagos se debió, entre otras cosas, al reclamo de no enviar a los hombres a una guerra contra las provincias vecinas. El gobierno de Buenos Aires sabía que la cuerda no podía tensarse sin poner en peligro el proyecto de formación de nuevas bases de sustentación del poder.

A fines de 1854, y ante los rumores de una nueva invasión federal desde Santa Fé, las Guardias Nacionales se reorganizaron en base a la normativa vigente y se designaron nuevos jefes para los regimientos de caballería. Dicha superioridad fue elegida de entre los alcaldes y tenientes alcaldes de cada partido. Paralelamente los jueces de paz se mantuvieron el mando de los cuerpos de infantería y las tensiones entre éstos y las autoridades militares no menguaron. ${ }^{43}$ Luego de derrotadas las incursiones federales de los ahora llamados «emigrados», las fuerzas fueron licenciadas de prestar servicio por el término de un año, días después se disolvieron los regimientos de GN de caballería y se cesanteó a sus jefes por haberse terminado los motivos que los habían reunido. En dicha oportunidad se exceptuó de dicha medida a los jefes a cargo de los regimientos de GN de la frontera. ${ }^{44} \mathrm{Al}$ año siguiente el proceso de reorganización continuó con la adecuación del Ejército de Línea y la nueva división de la Comandancia en tres departamentos. Luego de esto, el problema fronterizo se tornaría prioritario. ${ }^{45}$

\section{El control de la frontera}

En cuanto a las relaciones del gobierno de Buenos Aires con las parcialidades indígenas, especialmente con los llamados «indios amigos», éstas se mantuvieron inicialmente en calma. Misma situación se observó en la campaña norte pues hasta fines de 1854 las relaciones interétnicas incluyeron comitivas diplomáticas para pautar la paz con el nuevo gobierno y esporádicos ataques a establecimientos rurales que no impidieron las negociaciones. ${ }^{46}$ Sin embargo, las estrategias indígenas en esta coyuntura fueron pendulares, por un lado propiciaban un constante acercamiento al gobierno de Buenos Aires brindando ayuda militar contra indios rebeldes y, al mismo tiempo, se mantenían conversaciones con

Guardia Nacional (en adelante, GN), la ordenación definitiva de estas unidades se realizó años después. Ver Caletti, B., «Después de la tormenta ¿la calma?...cit.» Para diciembre de 1852, sin embargo, las GN ya suplantaban a las milicias en varios puntos y, durante el Sitio, el Ejército Federal se organizó con los regimientos de GN. Algunos de estos regimientos se movilizaron a los alrededores de la ciudad mientras otros se quedaron en la campaña. Ver Barcos, M. F. «Tratos, batallas y malones...», cit.

43. Canciani, L., «Es preciso, pues, regimentar: La organización de la Guardia Nacional de campaña. Buenos Aires, 1852-1862», Anuario del Instituto de Historia Argentina [En línea], n. ${ }^{\circ}$ 14, La Plata, 2014.

44. Ratto, Silvia, Redes políticas en la frontera bonaerense 1836-1873: crónica de un final anunciado, Bernal, Universidad Nacional de Quilmes, 2015.

45. Según Canciani, el decreto de 1855 no fue el origen de la reorganización de esta fuerza (que debería datarse en 1857) sino el fin de un tipo de organización que tuvo como principal preocupación los problemas entre Buenos Aires y la Confederación Argentina. «Es preciso, pues, regimentar...», cit.

46. Ratto, Silvia, Redes políticas en la frontera ..., cit. 
la Confederación Argentina enfrentada al Estado de Buenos Aires. Como consecuencia, la paz fronteriza no duró. ${ }^{47}$

Desde la llegada de Bartolomé Mitre al Ministerio de Guerra se venía considerando que el sistema de racionamiento aplicado hasta el momento mostraba debilidad, producto de este diagnóstico se buscó recortar las raciones y encarar la expansión fronteriza, cuestión que inicialmente fracasó. ${ }^{48}$ Sumado a esto, el intento de trasladar el pueblo de Tapalqué sin aprobación de los caciques generó la sublevación masiva de las tribus de indios amigos allí asentadas, quienes se unieron a la confederación ranquel liderada por Calfucurá y protagonizaron devastadores ataques a las poblaciones criollas. Esta nueva situación provocó el despoblamiento criollo de gran parte de la campaña centro-sur entre 1853 y 1855 y obligó a las autoridades del Estado de Buenos Aires a replantear el problema indígena retomando la pacificación por medio de una serie de tratados con los principales caciques del sur. ${ }^{49}$

\section{Otras dimensiones del control: los derechos de propiedad}

En cuanto a la política de tierras, en 1854 el gobierno de Buenos Aires designó una comisión que elaboró un proyecto general sobre las públicas que contemplaba disposiciones relativas a donaciones, ventas, enfiteusis y normas sobre trámites inconclusos iniciados durante el anterior gobierno de Rosas. Este proceso llamado «reparación» culminó recién en 1864 y fue sustancialmente influido por la decisión política de castigar al gobernador Rosas y a su círculo partidario. Para ello se estableció un criterio de legalidad que fundamentó lo que fue finalmente reconocido (las ventas de la década de 1830, algunas donaciones y los premios por combate) como lo que no (los premios por fidelidad). ${ }^{50}$ Cuando comenzó la revisión de la legislación rosista sobre tierras públicas, la primera reacción había sido la condena, sin embargo, la exposición de los datos del proceso de entrega de tierras fueron dejando al descubierto que algunos derechos debían contemplarse, por lo que finalmente predominó la idea que no todo podía ser enjuiciado y desconocido sin herir intereses concretos. ${ }^{51}$

Además del proceso de revisión, a partir de 1854 se reactivó la política de donaciones de parcelas en los ejidos de los pueblos de campaña. A nivel local, esta política fue central para la construcción del poder territorial de los vecindarios. No tanto por la cantidad de hectáreas entregadas —ínfima en comparación con la otorgada para estancias- sino por el número de familias a las que esta medida incluyó. Para ejecutar las delineaciones de

47. También influyó la incorporación de una nueva camada de oficiales militares y el proyecto de trasladar el pueblo de Tapalqué hacia las nacientes del arroyo homónimo sin el acuerdo de los caciques allí asentados.

48. Ratto, Silvia, Redes políticas en la frontera..., cit.

49. Lanteri, Sol y V. Pedrotta, «Tierras, armas y política...», cit.

50. Infesta, M. Elena y Marta Valencia, «Tierras, premios y donaciones. Buenos Aires, 1830-1860», Anuario IEHS, Tandil, 1987, pp. 177-213.

51. Valencia, Marta, Tierras públicas, tierras privadas, La Plata, AHPBA, 2005. 
pueblos y ejidos, así como para efectivizar las donaciones, se organizaron nuevas comisiones de notables denominadas «comisión de solares». Se ha comprobado que en varios pueblos el abanico de donatarios se amplió y diversificó con la incorporación de buena parte de extranjeros. ${ }^{52}$ Además, si bien los labradores seguían siendo dominantes entre los donatarios, en los partidos estudiados en profundidad, se observó la inclusión de ganaderos y comerciantes italianos, españoles y franceses en mayor proporción que antes. ${ }^{53}$ Así el elenco de beneficiados extranjeros superó ampliamente a los criollos y es plenamente observable en los recuentos de población posteriores. ${ }^{54}$ Por último, resalta el número de parcelas de comerciantes y funcionarios opositores al Sitio de Lagos como asî también de «conocidos federales» que empezaron a cumplir funciones para el nuevo gobierno del Estado de Buenos Aires. ${ }^{55}$

La reactivación de las donaciones durante el Estado de Buenos Aires se entiende en el marco de un conjunto de medidas tendientes a construir renovadas bases sociales de sustentación del poder. Tanto durante el rosismo, como en este periodo, se utilizaron como estrategia de captación de fidelidades territoriales en las luchas políticas que se operaban en el ámbito local. De esta manera la política de tierras fue parte de un proceso de afirmación institucional que operó en dos planos: obedeció a la idea de formar pueblos de labradores y y contribuyó a la «construcción» de un consenso in situ. ${ }^{56}$ Esta política indujo pero no determinó fidelidades automáticamente puesto que parece haber sido efectiva para construir bases sociales desde donde ejercer poder, cuando se articuló dentro de un conjunto simbólico y material mayor en la que adquirió varios sentidos. ${ }^{57}$

Todas las medidas de reorganización analizadas hasta aquí no pueden desligarse de otras tendientes a generar efectos ejemplificadores sobre la suerte que le depararía a quienes intentaran subvertir nuevamente el orden de Buenos Aires. En este sentido, consideramos que la política de «fusión» proclamada por el Estado de Buenos Aires vino precedida de largos meses donde imperó un clima revanchista y adoctrinador. Este clima fue sostenido por el gobierno de Pastor Obligado que, aun así, fue tildado por la prensa de El Nacional y La Tribuna de ejercer una política blanda. ${ }^{58}$

52. La inclusión europeos en el nuevo esquema de poder luego de Caseros se advierte en los nuevos notables, cuestión que señaló Garavaglia para Areco y la autora para Mercedes, Chivilcoy y Monte: Garavaglia, J. C., San Antonio de Areco...cit.; Barcos, M. Fernanda, Pueblos y ejidos..., cit.

53. Barcos, M. Fernanda, «Tratos, batallas y malones...», cit.

54. Barcos, M. Fernanda, Pueblos y ejidos...cit.; Contente, Claudia, «Las dos caras de la moneda: El impacto de la migración europea en la campaña de Buenos Aires, San Vicente y Almirante Brown (1869-1895)», Mundo Agrario, 18 (38), 2017.

55. Con conocidos federales nos referimos a los censados en los padrones de 1830 y 1831 . Sobre el tema ver Gelman, Jorge, «Unitarios y federales. Control político y construcción de identidades en Buenos Aires durante el primer gobierno de Rosas», Anuario IEHS, 19, 2004, pp. 359-391.

56. Barcos, M. Fernanda y Sol Lanteri, «Tierras públicas y construcción del Estado en Buenos Aires durante el siglo XIX. Las donaciones ejidales y condicionadas en una visión comparada», Boletín del Instituto de Historia Argentina «Emilio Ravignani», 2013, núm. 38, pp. 43-77.

57. Barcos, M. Fernanda, Pueblos y ejidos de la campaña bonaerense..., cit.

58. La prensa fue un actor central de la agitada vida política en la década de 1850 por su función performativa: instalaba temas y candidaturas, representaba a una causa o a un sector, contribuía a la movilización de 


\section{No hay olvido ni perdón para quienes osen subvertir el orden}

«En esta causa debe tenerse presente que si Lagos no se hubiese revelado contra la autoridad lejitima poniendo en peligro la seguridad de la patria que quiso entregar al Gral. Urquiza

[...] nadie habría tenido la desgracia de verse llevado ante los Tribunales por los actos cometidos durante la dictadura de Rosas»

Rufino de Elizalde, defensor de Manuel Troncoso.

Una vez finalizado el Sitio, el gobierno se comunicó a los jefes y oficiales que participaron en la rebelión que el gobierno otorgaba «amnistía». Como ya enunciamos, el «olvido y perdón» decretados duró poco y casi inmediatamente se mandaron embargar los bienes de los jefes Hilario Lagos, Gerónimo Costa y Benjamín Méndez. En el caso de Lagos, las estancias que poseía en los partidos de Rojas y Pergamino fueron embargadas. En ese último partido también fue apresado su hijo, quien puedo salir ileso de la situación gracias a las gestiones del político Lorenzo Torres. ${ }^{59}$ Esta situación es aparentemente llamativa porque fue Torres uno de los principales responsables del fracaso del Sitio, sin embargo, quizás sea necesario explorar con más detalle los lazos de camaradería de las diferentes facciones en pugna ${ }^{60}$ Enfrentadas políticamente e incluso en los campos de batalla, parece haberse mantenido cierta noción de que las pugnas eran circunstanciales y no llegaban a dañar por entero la solidaridad en cuestiones personales o económicas como tampoco la posibilidad de volver a formar coaliciones políticas en el seno de una facción.

Además de la persecución y embargos pautados para los sitiadores, durante el mes de septiembre de 1853 se iniciaron los llamados «grandes procesos» o «causas celebres». Estos se referían a los juicios desarrollados en contra de los involucrados en los crímenes del rosismo, especialmente los desatados por la Mazorca en 1840 y $1842 .{ }^{61} \mathrm{Al}$ mismo tiempo, también se juzgó en estos procesos a algunos de los personajes que habían prestado servicios al ejército sitiador, o habían cometido delitos públicos mientras duró el asedio. ${ }^{62}$ Algunos sitiadores, además, estaban acusados de los actos sucedidos en la déca-

la población, apoyaba o criticaba al oficialismo de turno. Ver Wasserman, F., «La ley y el orden. La libertad de imprenta en Buenos Aires durante la década de 1850», Quinto Sol, La Pampa, n. ${ }^{\circ}, 2018$, pp. 1-22.

59. No obstante los embargos, se prohibió su enajenación hasta el 27 de mayo de 1856 cuando dicho decreto quedó sin efecto por otro que autorizaba la venta de los bienes embargados. Registro Oficial..., cit., 1856, pp. 49-50.

60. AGN, Fondo Lagos, leg. 287.

61. La Mazorca se formó en torno a la Sociedad Popular Restauradora (un club adicto a la figura de Rosas) ya que sus líderes eran originalmente miembros de la entidad. Luego de un tiempo, empezó a actuar de modo separado como una especie de grupo parapolicial urbano encargado de amedrentar a los adversarios y, en momentos de violencia política puntual, fueron los responsables de casi un centenar de crímenes. Fue abolida oficialmente por Rosas en 1846.

62. Fueron juzgados Silverio Badia, Manuel Troncoso, Torcuato Canales, Fermín Suarez y José María Gutiérrez por «criminales famosos». Mateo Grela por sospechoso de asesinatos. Leandro A. Alem y Ciriaco Cuitiño por los mismos cargos. Antonino Reyes por los mismos cargos y su participación en el Sitio. Secundido 
da de 1840. No vamos a detenernos de modo exhaustivo en estos juicios porque son materia de otro trabajo pero si haremos mención de algunos aspectos que se mencionaron en estas causas y que estuvieron relacionadas con la rebelión de diciembre. ${ }^{63}$

Así como lo sucedido durante el rosismo había sido proclamado «en el olvido» por Urquiza, para Obligado «todo lo relacionado con el Sitio» debía tomar el mismo curso. No obstante, el gobernador volvió rápidamente sobre sus pasos argumentando que:

Un olvido sincero de los errores políticos que no han devorado por tantos años, sin que se entienda que hayan de quedar impunes los crímenes públicos y privados, sobre la cabeza de cuyos autores pende la cuchilla de la ley. ${ }^{64}$

La presión de esos años era muy fuerte, la prensa como portavoz de la «opinión pública» sostenía la necesidad de que el gobierno tomara medidas de escarmiento que fueran bien interpretadas por la sociedad. Para ello, en primer lugar era indispensable juzgar a los supuestos responsables de los crímenes de 1840 y 1842 y, en segundo término, a los partícipes en el levantamiento rural del $10^{\circ}$ de diciembre de 1852 . Hay cierto consenso entre los que han estudiado en profundidad estos juicios en que la exhumación de los crímenes endilgados a la mazorca respondió sobre todo a las necesidades del contexto de 1853. ${ }^{65}$ Durante el Sitio, los famosos personajes vinculados a Rosas volvieron a salir a la calle junto al ejército sitiador y esto seguramente reavivó los malos ánimos de la población de la ciudad de Buenos Aires. Por eso, finalizada la contienda, se denunció la presencia de los «famosos mazorqueros» y se buscó juzgarlos. Los juicios se iniciaron el 11 de septiembre de 1853, todo indica que los acusados ya estaban condenados desde el principio por una opinión pública que manifestaba el «público conocimiento» de sus crímenes pero no aportaba, en muchos casos, pruebas contundentes. ${ }^{66}$

Durante varios meses la sociedad porteña estuvo pendiente de los vaivenes de los juicios hasta que los mismos culminaron con fallos que iban desde la pena de muerte a la cárcel y los trabajos forzosos. En unos pocos casos algunos acusados de menor rango fueron dejados en libertad. En el caso de las ejecuciones, éstas se pudieron presenciar desde octubre hasta diciembre de 1853, la exposición de los cadáveres fue una práctica frecuente de esos días que colmó, y según los testimonios de la prensa, agotó a la sociedad de la época.

En relación con nuestro objeto de estudio, es interesante llamar la atención acerca del «encabezado» de los interrogatorios a los acusados pues éste da cuenta de la íntima

Pereyra por la muerte de Mariano Andrade y Federico Romero durante el Sitio, León Ortiz de Rosas por instigador de estos últimos crímenes.

63. AHPBA, Juzgado del Crimen, C. 41.3.155

64. Allende, A., La frontera y la campaña..., cit., p. 125.

65. Allende, A., «Iniciación del gobierno de don Pastor Obligado...», cit.; Saldías, A., Un siglo de instituciones..., cit.

66. González, C. T., El reclamo de Indalencia El terror en Buenos Aires, 1833-1853, Tesis de licenciatura, La Plata, Fahce, 2006. 
relación con el Sitio. Se iniciaban con: «Donde estuvo el declarante desde el 1. ${ }^{\circ}$ de diciembre del año anterior hasta que fue preso». ${ }^{67} \mathrm{Si}$ bien durante los procesos se acusó a Badia, Cuitiño y a Troncoso de haber participado del Sitio, estas acusaciones estaban más directamente ligadas con su actividad en la Mazorca. ${ }^{68}$

En cambio, en los casos de Antonino Reyes, Secundido Pereyra y León Ortiz de Rosas (todas figuras centrales durante el rosismo) la intervención que tuvieron en el Sitio fue bastante más importante en las acusaciones. En el caso de Reyes, ex Edecán de Rosas, tres de los cinco cargos que le imputó el Fiscal Agrelo se relacionaban con su participación en la rebelión del $1 .^{\circ}$ de diciembre. Los otros dos casos se relacionaron también íntimamente con la rebelión, Secundido Pereyra fue acusado de ser el autor de los famosos crímenes de los oficiales Andrade y Romero mientras que León Ortiz de Rosas fue acusado de instigador. Los crímenes a los que aludimos se produjeron durante las negociaciones en torno al fracasado Tratado de Paz del 9 de marzo de 1853. Durante esos días se había pautado la suspensión de armas conservando cada uno de los ejércitos sus posiciones. Sin embargo, el 5 de marzo los oficiales Andrade y Romero fueron apresados cuando se los encontró fuera de la línea pautada y asesinados en el saladero de Don León Ortiz de Rosas. Sus cuerpos aparecieron el día siguiente en una zanja con heridas de degüello, lanzazos y tiros. ${ }^{69}$ La brutalidad del crimen hizo que el gobierno de la ciudad pidiera explicaciones, si bien inicialmente los sitiadores desconocieron los hechos, luego entregaron los cuerpos para que se les diera sepultura. Este acontecimiento parece haber alterado fuertemente los ánimos de los vecinos de Buenos Aires y el clima de las negociaciones, la ceremonia fúnebre estuvo plagada de honores y simbolismo y quedó como un recuerdo popular del Sitio. ${ }^{70}$

En el juicio por estos crímenes no sabemos por qué se imputó solamente a Pereyra cuando los testimonios de la época hablan de una partida de por los menos cinco personas. Más allá de esto, Pereyra fue condenado por el juez Somellera a la pena de muerte en calidad de aleve y la misma fue efectivizada en el Hueco de los Sauces, emplazamiento donde habían sido asesinados los oficiales. ${ }^{71}$

Si bien la causa de Antonino Reyes no se encuentra disponible, Manuel Bilbao relató los sucesos del juicio en Vindicaciones. ${ }^{72}$ Reyes formaba parte de los individuos a los que le corría la amnistía decretada al finalizar el Sitio, no obstante, el 11 de agosto de 1853 fue

67. AHPBA, Juzgado del Crimen, 41-3-115.

68. Sobre Troncoso: - [Troncoso] tomé parte del Sitio «hasta que tubo lugar la rebelión que me tomó en Quilmes y me nombraron Sargento Mayor de la División de Videla». Sobre Silverio Badia: — «Es pública voz y fama que Silverio Badia era uno de los más acérrimos degolladores en los años 40 y 42 y asesino y ladrón en el 53». Sobre Antonino Reyes: — «ha sido el principal y más obstinado instigador de la guerra». González, C., El reclamo de Indalencia..., cit., p. 140.

69. Bustamante, J. L., Ensayo histórico de la defensa de Buenos Aires contra la rebelión del ex Coronel Hilario Lagos, Buenos Aires, Imprenta de «La Defensa», 1854.

70. Lettieri, A., La construcción de la República de la opinión ..., cit.

71. González, C. T., El reclamo de Indalencia ..., cit.

72. Bilbao, M., Vindicación y Memorias de Don Antonino Reyes, Buenos Aires, Ed. El Elefante Blanco (1883 [1998]). 
apresado en la Guardia de Luján por ser uno de los «criminales famosos». ${ }^{73}$ Desde su captura, y durante tres meses seguidos, el gobierno ordenó leer en las puertas de las iglesias de los pueblos un Edicto que convocaba a los vecinos a denunciar a Reyes.

Dos de los siete testigos que se presentaron en primer lugar lo denunciaron por los daños que habían sufrido durante el sitio. También Tomás Giménez declaró que era Reyes el responsable de todas las operaciones en el Cuartel General de San José de Flores, además de ser el causante de la desmoralización de las tropas del Sur. ${ }^{74}$ En un trabajo anterior pudimos recolectar las cartas que Reyes intercambió con Pedro Rosas y Belgrano y observar su particular estilo para manejar influencias. Las denuncias continuaron en el mismo tenor. Durante el juicio Reyes no renegó de su participación en la rebelión:

Tocó al coronel Lagos levantar en oposición al aislamiento y á las invasiones del Gobierno la Bandera de la Nacionalidad y de la concordia Argentina, y yo fui uno de los doce mil hijos de Buenos Aires que corrieron á sostener la integridad y la organización de la República, simbolizadas en el movimiento de la Guardia de Lujan. ${ }^{75}$

El fallo de mayo de 1854 lo condenó a muerte en calidad de aleve por la responsabilidad de los crímenes del periodo rosista, aunque posteriormente la Cámara de Justicia revisó el proceso y encontró varias irregularidades que terminaron por decláralo nulo. Reyes, no obstante, permaneció preso sin condena hasta que en junio del mismo año logró fugarse de la cárcel y exiliarse en Montevideo. Por la fuga fueron detenidos los guardias, los alcaldes y la parda Beatriz criada de Reyes. Su juicio continúo en rebeldía dictándose su sobreseimiento en junio de 1855 .

Luego de los espectáculos que brindaron estas causas parecía que la exaltación de la ciudad se encontraba controlada, sin embargo en la campaña los problemas continuaban. Para marzo de 1854 la situación volvía a ser inestable porque desde Santa Fe se organizaban partidas de salteadores y gavilleros, las autoridades plantaban la posibilidad de que fueran organizadas por los ahora llamados «exiliados» y avaladas por Urquiza. ${ }^{76}$ Situación que hemos podido comprobar mediante una carta que Reyes, recién fugado, le escribió a Lagos, en ella relataba su encuentro con Urquiza y las sugerencias del presidente de la Confederación respecto de realizar una reunión general de jefes para organizarse y plantear una nueva ofensiva. ${ }^{77} \mathrm{El}$ plan fue descubierto por el gobierno de Obligado y

73. Antonino Reyes ejerció como comandante del campamento de Santos Lugares de quien fue además su edecán. Después de la batalla de Caseros fue dado de baja pero luego Urquiza lo reincorporó al ejército como oficial mayor del Ministerio de Guerra del gobernador Vicente López y Planes. Se opuso a la revolución del 11 de septiembre de 1852 y se exilió en Montevideo. Regresó en diciembre junto al coronel Ramón Bustos, para unirse a la revolución del general Hilario Lagos. Fue ministro del gobierno provisional que dirigía el general Lagos, reemplazando en el cargo a Marcos Paz en enero de 1853.

74. Bilbao, M., Vindicación y Memorias..., cit.

75. Ibidem.

76. AHJM, JDP, 1854.

77. Leg. 27212 de julio de 1853. 
provocó una fuerte alarma que desató una ola de arrestos y destierros para quienes resultaban sospechosos de conspiración. ${ }^{78}$ En el apartado siguiente analizaremos algunos de estos casos.

\section{«Hay que escarmentar a la multitud de mazorqueros que viven entre nosotros»}

Uno de los primeros oficiales en ser buscado y perseguido fue Benjamín Méndez, jefe del Reg. 3. ${ }^{\circ}$ de GN durante el Sitio. Las ordenes eran claras para las partidas que lo buscaban: «los muertos no se escapan». ${ }^{79} \mathrm{La}$ misma orden era dada para el caso de encontrar al «facineroso Olmos» quien seguramente iba a cruzar a Buenos Aires para dirigirse al Sur. Es interesante la respuesta del Juez de Paz de Chascomús a la orden citada:

No estaría de más una pequeña fuerza de caballería con un jefe acreditado que se situase en el Río Salado o en este punto: las razones que me hacen indicar a Ud. esta medida son que Olmos a más de tener en este pueblo su casa y familia que no conviene por sus relaciones con algunos paisanos, fue algún tiempo jefe de la milicia y existen la mayor parte de todos sus oficiales de antecedentes mazorqueros algunos y otros que lo fueron de Clavero, aunque hoy se hallan trabajando... ${ }^{80}$

En este sentido la influencia de Olmos en el Sur era bastante similar a la de Pedro Rosas. La respuesta del Ministro Portela no se hizo esperar, se negaba a enviar fuerzas pero: «...ordena al Juez de Paz vigile y haga vigilar con todo celo y constancia a todas las personas que teniendo relaciones con el rebelde Olmos, o sus cómplices, puedan presentar en su conducta motivos de sospecha [...] remitiendo presos a los culpables» ${ }^{81}$ Como se desprende de estos dichos, la persecución no se agotaba en los cabecillas sino que incluía a todas las personas que tenían o habían tenido relación con los rebeldes. Todos los juzgados debían mandar asiduamente informes del siguiente tenor: El juez de paz «participa para conocimiento de S. E el Señor Gobernador que este partido goza de la más perfecta tranquilidad y que todos sus vecinos están dedicados a sus labores y tareas». ${ }^{82}$ Algunos jueces planteaban que el problema lo generaban los forasteros, eran éstos y no los lugareños los que «engañaban a los vecinos». Claramente con estos dichos, los jueces intentaban cargar sobre el anonimato de los extraños cualquier problema que pudiera generarse en sus pueblos. También había jueces, como el de Chivilcoy, que hacían hincapié en la influencia que tenía la oficialidad militar en los vecindarios pues no solo tenían propiedades en la campaña sino también relaciones con los notables y con los individuos potencialmente sujetos a leva.

78. Scobie, J. La lucha por la consolidación..., cit.

79. AGN, Estado de Buenos Aires, 28-6-1.

80. Ibidem.

81. Ibidem.

82. AHJM, JDP, 30 de agosto de 1853. 
Además de las persecuciones citadas, en muchos vecindarios se realizaron requisas para secuestrar las armas que quedaban de la rebelión de diciembre y detenciones. El accionar del juzgado de la ex Guardia de Luján (Mercedes) durante esos años muestra claramente el peso disciplinador y la influencia de la coyuntura bélica en las causas de detención. ${ }^{83}$ Solo a modo ilustrativo podemos citar un sumario contra Esteban Saint Hilayre que fue elevado al Juez del Crimen del Dto. Norte. El delito imputado fue «seductor en comisión de los enemigos del Estado». Hilayre fue declarado culpable y destinado a tres años de servicio. Otro caso fue el de Eduardo Larroque y Francisco Abadie por «esparcir noticias alarmantes sobre el estado de la campaña». En este caso solo se siguió el sumario contra Abadie mientras que Larroque fue sobreseído, quizás porque eran franceses y personajes importantes del vecindario. Podríamos seguir con más ejemplos pero creemos que estos alcanzan para pensar que «el estado de tranquilidad» que expresaban las editoriales de El Nacional y La Tribuna no era tal y lo que se experimentaba en la campaña era un verdadero estado de vigilancia.

El 4 de noviembre se produjo finalmente la invasión sospechada, ésta estuvo integrada por varios de los militares que participaron del Sitio y esta vez fue liderada por Gerónimo Costa nombrado «Jefe del Ejército Confederado del Río de La Plata». Según la Proclama del levantamiento, éste se proponía derribar al gobierno, abolir la Constitución y convocar una Convención Constituyente. El gobierno de Buenos Aires fue anoticiado del suceso y tomó medidas que hicieron fracasar rápidamente la invasión. Los «rebeldes» fueron derrotados por las fuerzas del Gral. Hornos cuatro días después de cruzar el Arroyo del Medio, en la localidad de Tala, con alrededor de 500 hombres. Lograron, no obstante, escapar al territorio de la Confederación. Paralelamente el gobierno había declarado el estado de sitio, movilizado a la Guardia Nacional y nombrado a Bartolomé Mitre Jefe del Estado Mayor. Luego de sofocado el peligro, se discutió ampliamente hasta dónde se debía perseguir a los sublevados, primero prevaleció el criterio de armar una fuerza capaz de invadir Santa Fé pero luego triunfó la idea de una paz armada. ${ }^{84}$

La inestabilidad de esos años fue permanente, en julio de 1855 el Estado de Buenos Aires confirmó los rumores sobre un nuevo intento de invasión organizado desde la provincia de Santa Fé. El mando de la nueva incursión pasaba ahora de Gerónimo Costa a José María Flores quien se encontraba nuevamente en las filas de los federales. ${ }^{85}$ En esta oportunidadad el gobierno de Buenos Aires estableció rápidamente una serie de medidas que permitieron detener la incursión en el pueblo de San Nicolás. Aun así, en enero de 1856 , los «rebeldes» volvieron a incursionar por la provincia con otros intentos de ataque

83. Belzunces, G. «Criminalidad, control y justicia de paz entre Rosas y Mitre. Mercedes (1853-1862), Anuario IEHS, 34 (1) 2019, pp. 31-58.

84. Los principales partidarios de la invasión eran Pastor Obligado, Nicolás Anchorena y Lorenzo Torres. Por medio de una especie de Convenio de Convivencia se volvió a la situación preexistente a la invasión pero la Confederación se comprometía a hacer retirar de Santa Fé a los militares que invadieron Buenos Aires y a los civiles que incitaron a la rebelión Las GN de caballería de campaña fueron nuevamente desmovilizadas luego de este acuerdo.

85. Citado por Saldías, A., Un siglo de instituciones..., cit., p. 87 
que fueron también sofocados. En la última incursión llegaron a Zárate e intentaron reunir adeptos hacia el interior de la campaña —emulando lo sucedido en diciembre de 1852 - pero no obtuvieron mucha adhesión.

Como se desprende de los hechos relatados, la tensión y vigilancia que se experimentaba en los pueblos era constante, durante esos meses la correspondencia entre el gobierno y los juzgados dando cuenta de la situación como impartiendo ordenes de «persecución» y «cárcel» era recurrente. La siguiente nota del Alcalde de las Saladas al juez de paz de Mercedes lo ilustra: «hago recorrer el cuartel diariamente con una partida para el cuidado del orden observando toda persona que se crea desconocida o sospechosa para remitirla a ese juzgado. Sé que en Chivilcoy se ha citado a todo el vecindario con el mismo motivo». 86

Para 1856 el gobierno de Buenos Aires no solo ya tenía experiencia en la dinámica de estas incursiones sino que, además, las estaba esperando. Ordenó condenar a muerte a todos los oficiales involucrados en las invasiones y, para ello, comisionó a Bartolomé Mitre y a Emilio Conesa. El primero estaba encargado de cargar contra José María Flores mientras que Conesa debía perseguir a Gerónimo Costa, este último y sus oficiales fueron apresados y fusilados en Villamayor.

\section{Reflexiones finales}

La construcción de un nuevo consenso socio-político en la provincia, exitoso en la ciudad, fue mucho más tardío y complejo en la campaña. Los años posteriores al sitio estuvieron signados por un estado de beligerancia casi continúo y en todas las direcciones. A la necesitad de reorganizar institucionalmente las zonas fronterizas — con todos los costos que eso implicaba ya que el éxito dependía de obtener poder territorial y dotarse de un funcionariado acorde - se sumaron los conflictos con la Confederación. Posteriormente se añadió la amenaza de parte de las tropas federales que huyeron a Rosario luego del Sitio, previo paso por los partidos del norte para recabar adeptos. Las posibilidades de éxito de estos levantamientos fueron relativizadas por parte de la historiografía, sin embargo, no fueron de ningún modo minimizadas por los contemporáneos. A la conflictividad interna se sumó la ofensiva indígena y posteriormente las desavenencias entre los sectores que aspiraban intervenir en las decisiones del gobierno de Buenos Aires ya que el bloque de unidad se empezó a fracturar a partir de 1856 entre un ala que podríamos denominar liberal y otra federal. ${ }^{87}$

En este trabajo analizamos los años inmediatamente posteriores al fracaso de la rebelión rural de diciembre de 1853 que puso Sitio a la ciudad de Buenos Aires por casi ocho meses. Luego del definitivo triunfo de los separatistas a mediados de julio de 1853, y con

86. AHJM, JDP, Nota del Alcalde de las Saladas al Juez de Paz de Mercedes, 28 de diciembre de 1855.

87. Entre la oficialidad, José María Flores y Pedro Rosas y Belgrano se apartaran de la política oficial en los años posteriores. 
el deseo de comenzar a modificar el estado de cosas vigente, el gobierno del futuro Estado de Buenos Aires se concentró en ordenar la campaña. Para ello tomó varias medidas importantes, sobre todo: reorganizó el aparato defensivo con la separación de las comandancias y el intento de ordenar las guardias nacionales, discutió los primeros proyectos de organización de las municipalidades y pudo establecer algunas, modificó el sistema impositivo y «ordenó» la política de tierras del rosismo. También envió al gobernador a visitar a los pueblos del norte y centro de la campaña para observar las situaciones que allí se suscitaban y para generar posibles alianzas con las familias predominantes de cada pueblo. Finalmente, conformó nuevas comisiones de solares encargadas de la política de donaciones de solares, quintas y chacras en los ejidos de los pueblos de la campaña.

El conjunto de estas medidas permitió a muchos extranjeros acceder a nuevos ámbitos de poder local ya que muchos integraron cargos en las municipalidades, en los nuevos establecimientos administrativos y fueron los principales beneficiarios de la nueva oleada de donaciones. Estas últimas si bien no fueron importantes en cuanto a la cantidad de hectáreas adjudicadas incluyeron un número importantísimo de pobladores, prueba de ello es el aumento de propietarios en los registros de contribución directa posteriores a 1855.

Paralelamente a la organización citada, se puso mucho énfasis en las medidas de índole represiva y disciplinaria: a la famosa prohibición del cintillo punzó le siguieron la activación de los embargos a los sublevados y cómplices, el juzgamiento a los partícipes de la Mazorca y del Sitio. Pero estas medidas no recayeron solo en los altos mandos puesto que la presión directa o indirectamente se ejerció sobre toda la población de la campaña. En estos primeros años el relevo de funcionarios vinculados al federalismo fue frecuente, al igual que el aumento de las medidas de control y vigilancia de la población. Estas últimas incluyeron interrogatorios programados y aleatorios, cárcel por sospechas de traición o complicidad con los «mazorqueros», destierros e incluso declaraciones oficiales donde se tildaba públicamente a tal o cual individuo de «enemigo del Estado» con toda la deshonra que el epíteto podría implicar.

Otro aspecto que es interesante observar es el siguiente: en las nuevas incursiones de los federales que habían emigrado a Santa Fé luego de la derrota del Sitio, el eje del conflicto se trasladó del oeste al norte de Buenos Aires. Como incursionaban desde Rosario, el gobierno de Buenos Aires destacó sus principales bastiones defensivos en los pueblos lindantes pero también porque el oeste estaba siendo extremadamente controlado. Todo parece indicar que estas rebeliones ya no reunían tantos adeptos como en el periodo inmediatamente posterior al inicio del separatismo porteño y consideramos que esto se relacionó con varias de las cuestiones que hemos señalado a lo largo de este trabajo. En este sentido la aparente decadencia del federalismo de antiguo cuño debió estar también relacionada con el control impuesto entre 1853 y 1856 y con la paulatina reconfiguración de la composición social de los vecindarios. Ésta si bien obedeció a los cambios sociales que implicó el nuevo patrón de desarrollo de la economía bonaerense (que vinculaba la provincia al mercado internacional a través de la exportación de lanas y expandía lentamente el sector de servicios) tuvo también impulso en una política gubernamental que encontra- 
ba en esta camada de europeos — con un peso creciente en los pueblos- el sujeto predilecto de su accionar. Estos sectores no estaban tan directamente vinculados al pasado de la provincia y esperaban nuevas oportunidades de participación socioeconómica y política. Prueba de ello es la importancia creciente que tuvieron en la política institucional de los años posteriores.

\section{Fuentes}

Archivo General de la Nación: Fondo Lagos, Fondo Saldías [Farini], Estado de Buenos Aires, Gobierno.

Archivo Histórico de la provincia de Buenos Aires: Juzgado de Paz, Juzgado del Crimen, Escribanía Mayor de Gobierno.

Archivo Histórico Judicial de Mercedes: Juzgado de Paz de la Guardia de Luján, Juzgado de Paz de Mercedes.

Periódicos: El Nacional (1853), La Tribuna (1853).

\section{Fuentes editas}

Bilbao, Manuel, Vindicación y Memorias de Don Antonino Reyes, Buenos Aires, Ed. El Elefante Blanco (1883 [1998]).

Bustamante, José. Luis., Ensayo bistórico de la defensa de Buenos Aires contra la rebelión del ex Coronel Hilario Lagos, Buenos Aires, Imprenta de «La Defensa», 1854.

Registro Oficial de la Provincia de Buenos Aires, Buenos Aires, Imprenta de «El Orden», 1853.

Registro Oficial del Estado de Buenos Aires, Buenos Aires, Imprenta de «El Orden», 1854, 1855.

\section{Bibliografía general}

Allende, Andrés, «Iniciación del gobierno de don Pastor Obligado en la provincia de Buenos Aires en 1853», Trabajos y comunicaciones, 3, La Plata, 1952, pp. 5-17.

—, «Repercusión de la Revolución del 11 de septiembre en el interior de la provincia de Buenos Aires», Trabajos y comunicaciones, 4, La Plata, 1954, pp. 14-18.

—, La frontera y la campaña del Estado de Buenos Aires (1852-1853), La Plata, Fahce, 1957.

Aramburu, Mariano, «El debate legislativo de la constitución del Estado de Buenos Aires (1854). Los conceptos de nación, soberanía y estado», PolHis, Año 9, n. ${ }^{\circ}$ 17, Buenos Aires, 2016, pp. 170-209.

Banzato, Guillermo, «Las confiscaciones y embargos de Rosas en Chascomús, 1840-1852», Cuadernos del PIEA, n. ${ }^{\circ}$ 15, Buenos Aires, 2001, pp. 5-32.

Barcos, M. Fernanda, «Expresiones políticas y movilización popular en los pueblos de la campaña de Buenos Aires. La Guardia de Luján y el Sitio de Lagos (1852-1854)», Nuevos Mundos, Mundos Nuevos [En línea], Debates, París, 2012.

—, Pueblos y ejidos de la campaña bonaerense: una historia sociojurídica de los derechos de propiedad y la conformación de un partido: Mercedes, 1780-1870, Rosario, Prohistoria, 2013. 
—, «Tratos, batallas y malones. El accionar indígena en la frontera sur durante el sitio a la ciudad de Buenos Aires», Corpus [En línea], vol. 7, núm. 1, 2017.

—, «Las armas en reposo: la intervención del Congreso General Constituyente de 1853 y las disputas por la representación política durante el Sitio a Buenos Aires», Pasado Abierto [En línea], 4.7, 2018.

Barcos, M. Fernanda y Sol Lanteri, «Tierras públicas y construcción del Estado en Buenos Aires durante el siglo XIX. Las donaciones ejidales y condicionadas en una visión comparada.», Boletín del Instituto de Historia Argentina «Emilio Ravignani», núm. 38, Buenos Aires, 2013, pp. 43-77.

Belzunces, G., «Criminalidad, control y justicia de paz entre Rosas y Mitre. Mercedes (1853-1862), Anuario IEHS, 34 (1), 2019, pp. 31-58.

Bosch, Beatriz, Urquiza y su tiempo, Buenos Aires, Ed. Universitaria de Buenos Aires, 1971.

Caletti, Barbara, «Esa palabra federación, es mágica, atractiva como el imán. Algunos apuntes sobre la cultura política popular en el levantamiento de diciembre de 1852», XII Jornadas Interescuelas Departamentos de Historia, Universidad Nacional del Comahue, 2009.

—, «Después de la tormenta ¿la calma?: Ejército y Milicias en la campaña porteña tras Caseros», Coordenadas. Revista de Historia Local y Regional, n. ${ }^{\circ}$ 1, Río Cuarto, 2014, pp. 59-89.

Canedo, Mariana, «Mucho más que una cuestión de medidas. Los agrimensores del Departamento Topográfico por los pueblos del Estado de Buenos Aires. La comisión del Norte, 1854-1856», en Garavaglia, Juan Carlos y Pierre Gautreau (comps.), Mensurar la tierra, controlar el territorio. América Latina siglos XVIII y XIX, Rosario: Prohistoria, 2011, pp. 259-294.

—, «... en la Campaña se ha despertado un espíritu maligno». Estrategias políticas y divisiones sociales en las primeras elecciones municipales (Estado de Buenos Aires, 1855)», Illes i Imperis 21, 2019.

Canciani, Leonardo, «El coronel Don Benito Machado. Un comandante de Guardias Nacionales en la frontera sur bonaerense [1852-1880]». Mundo Agrario, 12 (24), 2012, Recuperado a partir de $<$ https://www.mundoagrario.unlp.edu.ar/article/vie $>$.

—, «Es preciso, pues, regimentar»: La organización de la Guardia Nacional de campaña. Buenos Aires, 1852-1862», Anuario del Instituto de Historia Argentina [En línea], n. ${ }^{\circ}$ 14, La Plata, 2014.

Cárcano, Ramón, De Caseros al 11 de septiembre: 1851-1852, Buenos Aires, Mendesky, 1946.

Contente, Claudia, «Las dos caras de la moneda: El impacto de la migración europea en la campaña de Buenos Aires, San Vicente y Almirante Brown (1869-1895)», Mundo Agrario, 18 (38), e052. <https://doi.org/10.24215/15155994e052>.

Corva, M. Angélica, Constituir el gobierno, afianzar la justicia. El Poder Judicial de la provincia de Buenos Aires (1853-1881), Rosario/Buenos Aires, Prohistoria Ediciones-Instituto de Historia del Derecho, 2014.

Cutrera, M. Laura, «Que todavía no se ha acabado esto». Sobre el fin del Negocio Pacífico de Indios después de Caseros», Anuario del Instituto de Historia Argentina, n. ${ }^{\circ}$ 13, La Plata, 2013, pp. 125-156.

Díaz, Benito, Los juzgados de paz de campaña de la provincia de Buenos Aires (1821-1854), La Plata, Universidad Nacional de La Plata, 1959.

Eujenian, Alejandro, «La nación, la historia y sus usos en el Estado de Buenos Aires, 1852-1861», Anuario IEHS, n. ${ }^{\circ} 27$, Tandil, 2012, pp. 57-83.

-, El pasado en el péndulo de la política. Rosas, la provincia y la nación en el debate político de Buenos Aires, 1852-1861, Bernal, UNQui Editorial, 2015. 
Fradkin, Raúl O., La historia de una montonera. Bandolerismo y caudillismo en Buenos Aires, 1826, Buenos Aires, Siglo XXI, 2006.

Garavaglia, Juan Carlos, «De Caseros a la guerra del Paraguay: el disciplinamiento de la población campesina en el Buenos Aires posrosista (1852-1865)», en Garavaglia, J. C., Construir el estado, inventar la nación. El Río de la Plata, siglos XVIII-XIX, Buenos Aires, Prometeo, 2007, pp. 311342.

—, San Antonio de Areco, 1680-1880, Rosario, Prohistoria, 2009.

-, La disputa por la construcción nacional argentina. Buenos Aires, la Confederación y las provincias (1850-1865), Buenos Aires, Argentina, Prometeo, 2015.

Gelman, Jorge y M. Inés Schroeder, «Juan Manuel de Rosas contra los estancieros: Los embargos a los «unitarios» de la campaña de Buenos Aires», Hispanic American Historical Review, 83:3, 2003, pp. 487-520.

—, «Unitarios y federales. Control político y construcción de identidades en Buenos Aires durante el primer gobierno de Rosas, Anuario IEHS, 19, Tandil, 2004, pp. 359-391.

Gelman, Jorge y Daniel Santilli, «¿Cómo explicar la creciente desigualdad? La propiedad de la tierra en Buenos Aires entre 1839 y 1867», en Gelman, J. (coord.), El mapa de la desigualdad en la Argentina del siglo XIX, Rosario, Prohistoria, 2011, pp. 171-218.

González Bernaldo, Pilar, «Sociabilidad, espacio urbano y politización en la ciudad de Buenos Aires (1820-1852)», en Sabato, Hilda y A. Lettieri (Comps.), La vida política en la Argentina del siglo XIX. Armas, votos y voces, Buenos Aires, FCE, 2003, pp. 190-204.

González, Cristina, El reclamo de Indalencia El terror en Buenos Aires, 1833-1853, Tesis de licenciatura, La Plata, Fahce, 2006.

Halperin Donghi, Tulio, Proyecto y construcción de una nación (1846-1880), Buenos Aires, Emecé, 1995.

Infesta, M. Elena y Marta Valencia, «Tierras, premios y donaciones. Buenos Aires, 1830-1860», Anuario IEHS, Tandil, 1987, pp. 177-213.

Lanteri, Sol y Victoria. Pedrotta, «Tierras, armas y política en la frontera sur bonaerense durante la década de 1850. Los «indios amigos», Maicá y Villa Fidelidad», Anuario del Instituto de Historia Argentina [En línea], vol. 18, n. ${ }^{\circ}$ 1, La Plata, 2018.

Lettieri, Alberto, «La construcción del consenso político en la Argentina moderna. Poder político y sociedad civil en Buenos Aires, 1852-1861», Secuencia. Revista de Historia y Ciencias Sociales, 40, 1998, pp. 121-165.

- La construcción de la República de la opinión. Buenos Aires frente al interior en la década de 1850, Buenos Aires, Prometeo, 2006.

Míguez, Eduardo, «Guerra y orden social en los orígenes de la nación argentina, 1810-1880», Anuario del IEHS, n. ${ }^{\circ}$ 18, Tandil, 2003, pp. 17-38.

—, Bartolomé Mitre. Entre la Nación y la Historia, Buenos Aires, Edhasa, 2018.

Minutolo, Cristina, «El Sitio de Buenos Aires y la venta de la escuadra de la Confederación, Boletín del Instituto de Historia Argentina «Dr. Emilio Ravignani», núm. 7, Buenos Aires, 1958.

Ratto, Silvia, «Haremos lo posible para asegurar y tranquilizar la frontera. La defensa de la frontera bonaerense durante la década de 1850», en Garavaglia, Juan Carlos; Juan Pro Ruiz y Eduardo Zimmermann (Coords.), Las fuerzas de la guerra en la construcción del Estado: América Latina, siglo XIX, Rosario, Prohistoria, 2012, pp. 357-380.

-, Redes políticas en la frontera bonaerense 1836-1873: crónica de un final anunciado, Bernal, Universidad Nacional de Quilmes, 2015. 
Sáenz Quesada, M., El Estado rebelde, Buenos Aires entre 1850/1860. Buenos Aires: Editorial de Belgrano, 1982.

Saldías, Adolfo, Un siglo de instituciones, Buenos Aires en el centenario de la Revolución de Mayo, La Plata, s/e, 2010.

—, Historia de la Confederación Argentina, Buenos Aires, El Ateneo, T. III, 1951.

Scobie, James, El significado de la Revolución de Septiembre, Duke University Press, 1961.

—, La lucha por la consolidación de la nacionalidad argentina, 1852-1862, Buenos Aires, Hachette, 1964.

Valencia, Marta, Tierras públicas, tierras privadas, La Plata, Archivo Histórico de la provincia de Buenos Aires, 2005.

Wasserman, Fabio, «La ley y el orden. La libertad de imprenta en Buenos Aires durante la década de 1850», Quinto Sol [En línea], 2018.

Yangilevich, Melina, «Prefecturas, comisarías de campaña y construcción estatal en la Provincia de Buenos Aires (Argentina) a mediados del siglo XIX», Secuencia, núm. 102, septiembre-diciembre, 2018, pp. 70-99.

Zubizarreta, Ignacio, «Politización y transformaciones sociales en los pueblos de campaña del Estado de Buenos Aires, 1852-1861», Diálogos Revista Electrónica de Historia, 19 (2) [En línea], Julio-Diciembre, 2018.

—, «Whistle-stop en carruaje: Los viajes de los gobernadores a los pueblos bonaerenses, 18541858», Población E Sociedad [en línea], vol. 26 (1), 2019, pp. 120-143. 